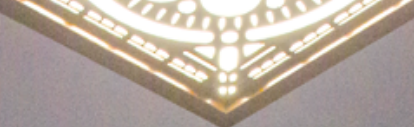

\title{
THE JUDAICA SUITE
}

Author:

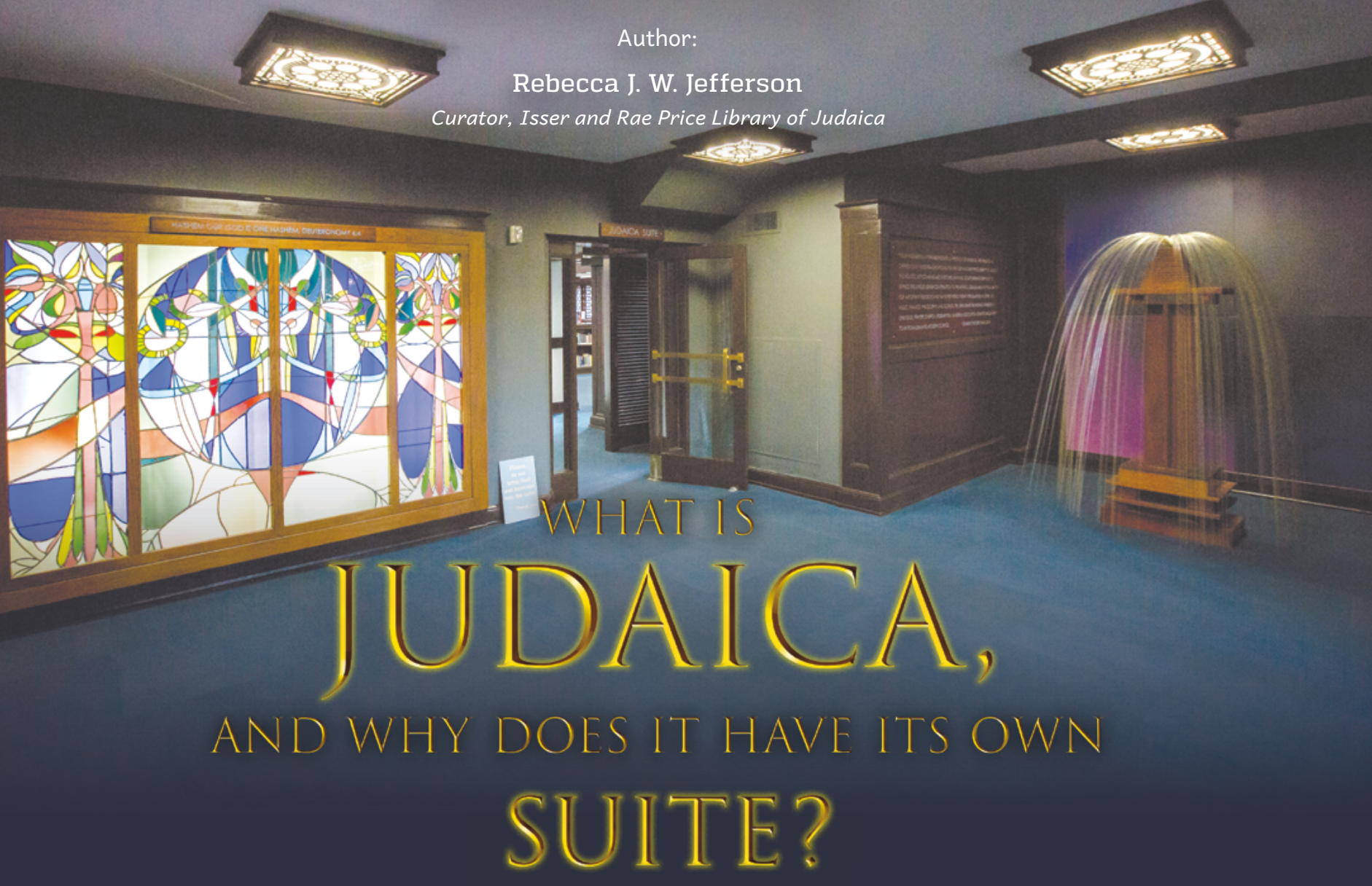

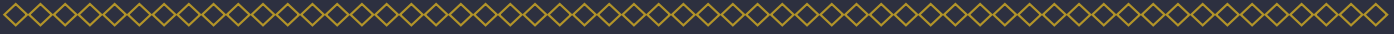

These are questions you may be asking yourself as you encounter this article. The Judaica in question refers to the collection of books and other materials belonging to the Isser and Rae Price Library of Judaica at the University of Florida. The term "Judaica" generally refers to objects of Jewish ritual and custom, but in a library setting it means anything written by or about the Jewish people, Such libraries also tend to hold "Hebraica" and "Yiddica" which are bibliographer's term to describe works written in Hebrew and Yiddish: two major Jewish languages. The Price Library has all of these and more; in fact, it holds over 120,000 items in over forty languages and from over fifty countries around the world. The question of why UF's Judaica Library has its own "Suite" also ties into the question of how we came to acquire such an impressive collection.
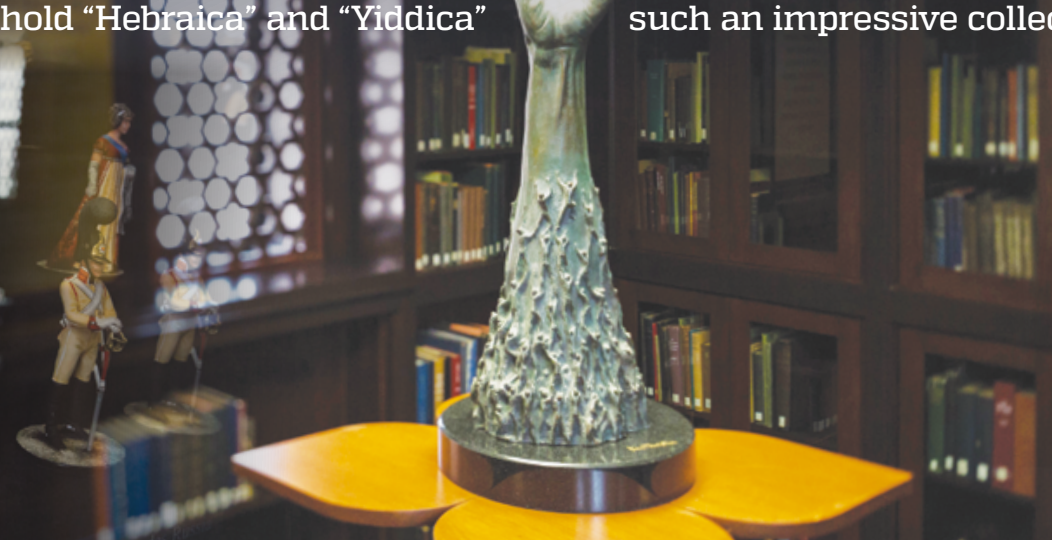


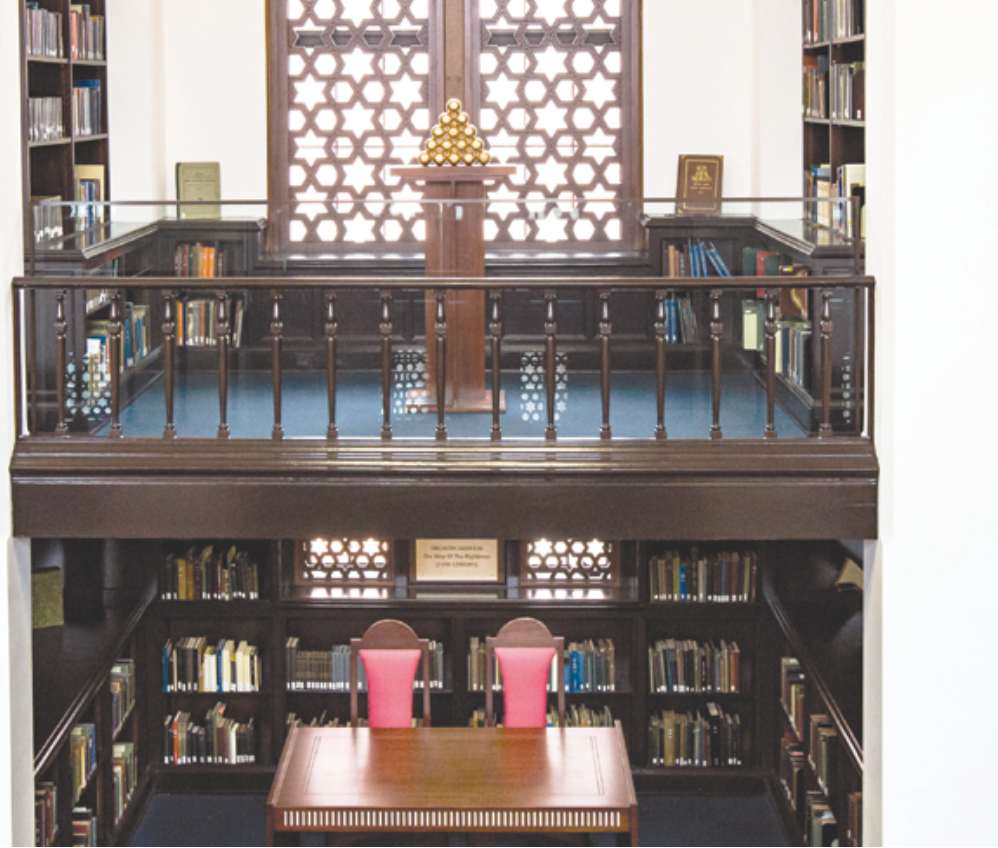

Fig.4 - Another view of the Judaica Suite from second floor after 2014 redesign

matching chairs. The tables and chairs are often moved around to accommodate the main lecture hall's many uses, which include meetings, classes, and events. A large canvas panel at the end and in the center of the room uses a technique known as "black on black artwork' to allow the subtle image of the Star of David to emerge as you stare at it. The Star-or, more accurately, the Shield of David-first emerged in the Middle Ages, inspired by medieval Arabic literature, as a symbol of protection. It did not have religious significance, and it only became fully associated with Judaism after some Jewish communities in the early modern era began using it as their official seal and later as a sign on their community buildings. But more than artwork, the canvas serves the purpose of blocking the unattractive exit doors, while its height and dark tone draws the eye up and around the room, soaking in the warm colors of the alcoves while appreciating the light expanse of the tall ceilings and arched windows.
Standing opposite this artwork, creating another focal point, is a wooden cabinet, known as an ark, which Treister designed to hold the Price Library's Torah scroll (Fig.5). Our unique scroll, handwritten in Russia in the 1930s, was donated to the Library by Isser and Rae's daughters, Eunice Zisser and Florence Schemer. The

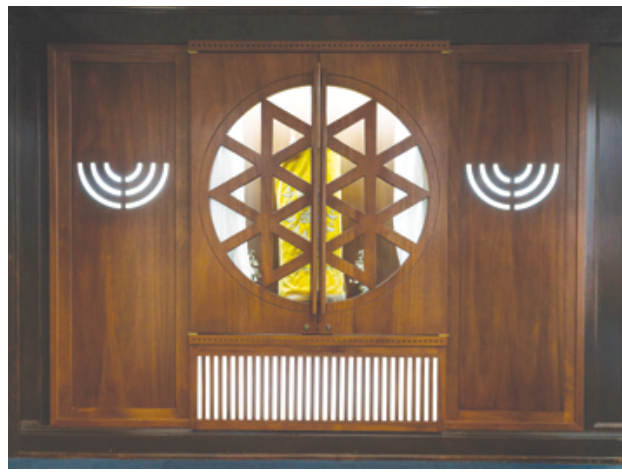

Fig.5 - The Ark

ark features another image in its carvings: the menorah (lamp).

The menorah is one of the oldest symbols of the Jewish faith, first appearing in the Torah (the Five Books of Moses) as the light fixture used inside the tabernacle, or portable temple, carried by the Israelites in the wilderness.

Next to the ark, in a separate space, enclosed by a door, one finds the Harold Hanson Rare Book Room. Inside this room, in addition to another handmade table, one encounters copies of significant Hebrew books printed during the handmade paper era (16th to 18th century). Many of the volumes are religious works: Bibles, prayer books, works of theology and religious commentary, including the first English version of the Hebrew prayers printed in America (1766) and the first Hebrew Bible printed in America (1814).

The "Judaica Suite Upper Arts Gallery," in addition to holding the library's rare Hebraica, Yiddica, Jewish Americana, and Jewish music collections, contains numerous sculptures created by Kenneth Treister. Here one can see many different types of sculpture, from figurative bronze busts of historic Jewish personalities to abstract sculptures in cascading, bursting or sharp pointed sticks of bronze symbolizing key Jewish (but also universal) experiences such as "slavery to freedom," "diaspora," and "six million souls 
